\title{
Accuracy Evaluation of Long-Range Reflectorless Distance Measurement
}

\author{
Ragab Khalil1,2 \\ ${ }^{1}$ Civil Engineering Dept., Faculty of Engineering, Assiut University, Assiut, Egypt \\ ${ }^{2}$ Landscape Architecture Dept., Faculty of Environmental Design, KAU, Jeddah, Saudi Arabia \\ Email: khalilragab@yahoo.com
}

Received 1 July 2015; accepted 15 August 2015; published 19 August 2015

Copyright (c) 2015 by author and Scientific Research Publishing Inc.

This work is licensed under the Creative Commons Attribution International License (CC BY). http://creativecommons.org/licenses/by/4.0/

(c) $\underset{\mathrm{EY}}{\mathrm{BY}}$ Open Access

\begin{abstract}
Reflectorless total station (RLTS) has made it possible for only one person to carry out field measurements and inaccessible points can be measured with relative ease. There is no sufficient information about the accuracy of these instruments for the long range measurements. This paper attempts to evaluate the accuracy of reflectorless distance measurements ranging up to $1000 \mathrm{~m}$ and to determine the surface area needed for such measurements at different incidence angles. An experiment was carried out to examine what effect surface material, target size and incidence angle had on distance measurement. In this experiment 10 different distances were measured using targets of 6 different materials and 4 different sizes at 5 different incidence angles. To properly evaluate the results, a special supporting base was designed and manufactured for holding the reflecting targets to ensure accuracy in the evaluation. Based on the accuracy analysis of a lot of testing results, the conclusions that were drawn indicated that the target size had a great effect on the accuracy if the incidence angle was between $15^{\circ}$ and $30^{\circ}$.
\end{abstract}

\section{Keywords}

Accuracy, Reflectorless, Target Area, Material, Incidence Angle

\section{Introduction}

Total station is widely used to survey topography and monitor land form, land use, geomorphic change detection of rivers, streams, beaches and mass wasting of hill slopes [1]. It is also used in building construction layout [2], dynamic deformation of bridges [3], cultural heritage documentation [4] and many other engineering applications. In the 1990s, a powerful visible laser beam was used for measurements to almost any surface without the use of retroprisms [5]. Many of today's total stations have integrated this reflectorless EDM technology [6]. As 
reflectorless total station (RLTS) has made it possible for only one person to carry out field measurements and inaccessible points can be measured with relative ease, they become widely used by surveyors [2] [4] [7]-[10]. It is increasingly becoming a standard surveying technique [11]. In order to ascertain the accuracy of the RLTS at short range distances, several studies were carried out. The accuracy of RTLS was investigated by [9] for distances up to $100 \mathrm{~m}$, by [2] for distances up to 300 feet ( $\cong 90 \mathrm{~m})$, by [12] for distances up to $60 \mathrm{~m}$ and by [5] for distances up to $50 \mathrm{~m}$.

This paper studies the effect of target material, target size and incidence angle of laser beam on the accuracy of reflectorless measurements for distances up to $1000 \mathrm{~m}$. A series of experimental measurements for 10 different distances were carried out using targets of 6 different materials and 4 different sizes at 5 different incidence angles. The distances obtained by reflectorless surveys were compared to the distances obtained by prism surveys. As the result of these comparisons, accuracy analyses were performed to draw conclusions about the influence of the mentioned parameters on the accuracy of reflectorless measuring.

\section{Instrumentation and Targets}

The total station used in this research was TOPCON GPT-7501 (7W2024). Its specifications [13] stated that its reflectorless measuring range was $(1.5 \mathrm{~m}-250 \mathrm{~m})$ with accuracy $\pm 5 \mathrm{~mm}$ in the normal mode and $(5 \mathrm{~m}-2000 \mathrm{~m})$ with accuracy $\pm(10 \mathrm{~mm}+10 \mathrm{ppmxD})$ in the long mode. Its accuracy in prism measuring mode is $\pm(2 \mathrm{~mm}+2$ ppmxD). A weather station SKYMASTER (No.21244) was used to measure the temperature, atmospheric pressure and humidity during the experimental work. The materials used in this study were selected to represent the most frequent materials that appeared in the surveyor's field work. 6 different materials: concrete, rock, red brick, wood, steel and aluminum were used as targets. To determine the surface area needed for the measured distance, 4 target sizes: $5 \mathrm{~cm} \times 5 \mathrm{~cm}, 10 \mathrm{~cm} \times 10 \mathrm{~cm}, 20 \mathrm{~cm} \times 20 \mathrm{~cm}$ and $30 \mathrm{~cm} \times 30 \mathrm{~cm}$ were tested. The targets were prepared in rectangular shapes so that one side increases $3 \mathrm{~cm}$ over the other to support the target on the supporting base and secure a clear area of the above dimensions. The total number of targets is 24,4 targets of different sizes for each of the 6 materials.

\section{Special Supporting Base}

A special supporting base was essential so that the targets could be properly and accurately placed. A simple base of (U) shape cross section was designed. It is $2 \mathrm{~cm}$ wide, $3 \mathrm{~cm}$ depth and $20 \mathrm{~cm}$ long with a screw on the rear plane so that the fastening materials to it are facilitated. It is made by stainless steel and manufactured to secure that the internal surface of the front plane must be on the center of the screw on its bottom. A horizontal circle was added to facilitate rotating the target to the needed incidence angle of the laser beam on the target surface as shown in Figure 1. The designed base was calibrated using reflector sheet. Two distances 10 and 50 $\mathrm{m}$ were measured using steel tape and total station with normal prism, then the prism was replaced by the designed base and a reflector sheet was hold on it. The distances were re-measured on the reflector sheet and compared to those on the prism. The distances measured to the reflector sheet were found to be longer than those measured on the normal prism by $1.0 \mathrm{~mm}$. This means that the surface of each material has a systematic deviation of $1.0 \mathrm{~mm}$, on the sight direction, from the corresponding point of the prism center. This value must be subtracted from each measured distance before its comparison to the measured distance on the prism. Consequently, after the calibration of the special supporting base, it could be used for the experiments, as distances measured to the prism could be compared with those measured to any other material.

\section{Experimental Procedure}

The procedure that was applied is the following:

1) A line of $1000 \mathrm{~m}$ length is marked with nails every $100 \mathrm{~m}$ on a street near King Abduaziz University as shown in Figure 2. There is a wall parallel to the established line and about $4 \mathrm{~m}$ apart.

2) The instrument is set up on the first point and its setting is modified to measure distance in fine mode and repeats the measurements 10 times.

3) The prism is centered on the next point, $100 \mathrm{~m}$ away. The distance between the instrument and the prism is measured after setting the instrument in prism mode.

4) The prism is removed from the tribrach and the special base is installed on it. The instrument's telescope is 

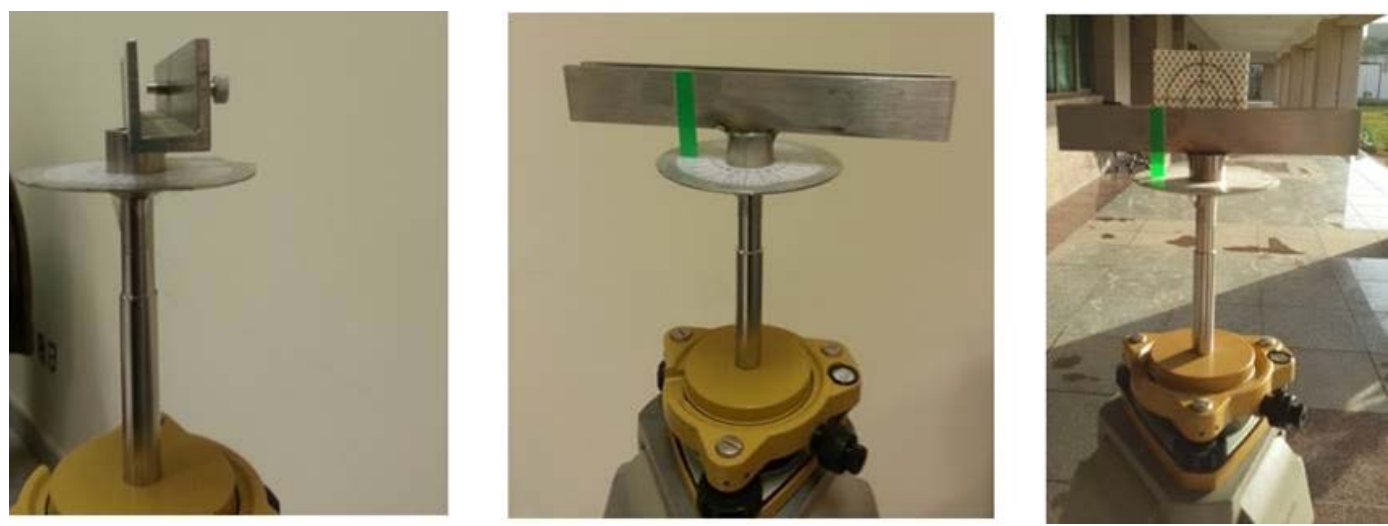

Figure 1. Special base for supporting the targets.

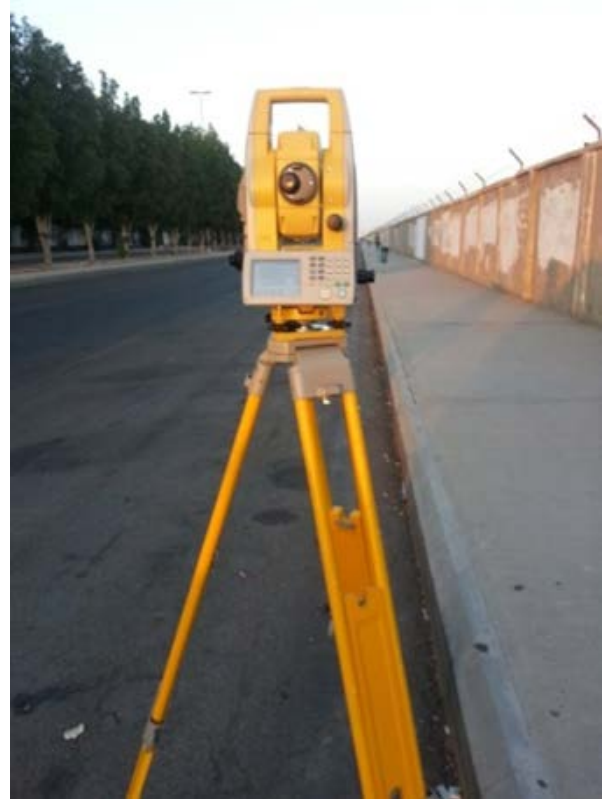

Figure 2. Experiment site.

not moved during these changes. All 24 targets used in the experiment are in turn-according to the target size-installed on the base and the distance to each one measured after setting the instrument in reflectorless mode. The reflectorless distance measurements were carried out at 5 different incidence angles of the laser beam on the surface, $0^{\circ}$ (normal), $15^{\circ}, 30^{\circ}, 45^{\circ}$ and $60^{\circ}$.

5) Steps 3 and 4 are repeated for the next 9 points, i.e. distances $200 \mathrm{~m}$ to $1000 \mathrm{~m}$.

\section{Results}

The difference between the measured distance on the prism $\left(D_{\mathrm{P}}\right)$ and the reflectorless measured distance on each material $\left(\mathrm{D}_{\mathrm{NP}}\right)$ was calculated using Equation (1)

$$
\triangle D=D_{P}-D_{N P}
$$

The acceptable value of $\Delta D$ is given by the Equation (2) [5] for the desired confidence level ( $x$ )

$$
\begin{gathered}
-x \cdot \sigma_{\Delta D} \leq \Delta D \leq x \cdot \sigma_{\Delta D} \\
\sigma_{\Delta D}=\sqrt{\sigma_{D_{R}}^{2}+\sigma_{D_{R L}}^{2}}
\end{gathered}
$$


where:

$\sigma_{D_{R}}=$ error of the distance measurement on the prism according to the manufacturer;

$\sigma_{D_{R L}}=$ error of the reflectorless distance measurement according to the manufacturer.

The acceptable values of the difference $\Delta D$ for confidence levels of $95 \%$, for instrument used are:

Normal mode: $\pm 5.39 x_{95 \%}= \pm 10.5 \mathrm{~mm}$

Long mode (up to $1000 \mathrm{~m}$ ): \pm (10.2 to 20.1$) x_{95 \%}= \pm$ (19.89 to 39.2$) \mathrm{mm}$

The differences $\Delta D$ in $\mathrm{mm}$ for the measured distances are summarized in Tables 1-10. The symbol (------) means that the instrument did not measure the distance to the target. The values of the differences $\Delta D$, which are unacceptable for confidence level $95 \%$, appear in bold. The tables show that in general, the reflectorless distances are shorter than distances measured on prism except for distances measured to targets of size $30 \mathrm{~cm} \times 30$ $\mathrm{cm}$ at incidence angles $30^{\circ}, 45^{\circ}$ and $60^{\circ}$. This may be because of the divergence of the laser beam over the target

Table 1. Deviations in the measured distances at incidence angle $=0^{\circ}$ for targets 5 and $10 \mathrm{~cm}$.

\begin{tabular}{|c|c|c|c|c|c|c|c|c|c|c|c|c|}
\hline \multirow[b]{3}{*}{ Dist } & \multicolumn{6}{|c|}{ Target size $5 \times 5$} & \multicolumn{6}{|c|}{ Target size $10 \times 10$} \\
\hline & \multicolumn{6}{|c|}{ Dmm } & \multicolumn{6}{|c|}{ Dmm } \\
\hline & Concrete & Rock & Brick & Wood & Steel & Aluminum & Concrete & Rock & Brick & Wood & Steel & Aluminum \\
\hline 100 & -4 & -1 & -2 & -4 & -4 & -5 & 0 & 1 & -1 & -1 & -3 & -3 \\
\hline 200 & -7 & -7 & -5 & -10 & -2 & -10 & -5 & -5 & -9 & -6 & -9 & -8 \\
\hline 300 & -8 & -5 & -15 & -11 & -15 & -12 & -5 & -4 & -15 & -5 & -8 & -4 \\
\hline 400 & -13 & -12 & -6 & -14 & -8 & -8 & -8 & -4 & -12 & -11 & -9 & -7 \\
\hline 500 & -4 & -9 & -8 & -8 & -8 & -3 & -11 & -12 & -9 & -10 & -13 & -17 \\
\hline 600 & -26 & -22 & -17 & -6 & -14 & -27 & -12 & -14 & -15 & -21 & 1 & -15 \\
\hline 700 & -25 & -14 & -24 & -12 & -18 & -16 & -16 & -20 & -21 & -17 & -9 & -2 \\
\hline 800 & ----- & ----- & ----- & ----- & ----- & ------ & ----- & ----- & ----- & ------ & ----- & ----- \\
\hline 900 & ----- & ----- & ------ & ------ & ------ & ----- & ----- & ------ & ------ & ----- & ------ & ----- \\
\hline 1000 & ------ & ------ & ----- & ------ & ----- & ----- & ------ & ------ & ------ & ------ & ------ & ----- \\
\hline
\end{tabular}

Table 2. Deviations in the measured distances at incidence angle $=0^{\circ}$ for targets 20 and $30 \mathrm{~cm}$.

\begin{tabular}{|c|c|c|c|c|c|c|c|c|c|c|c|c|}
\hline \multirow[b]{3}{*}{ Dist } & \multicolumn{6}{|c|}{ Target size $20 \times 20$} & \multicolumn{6}{|c|}{ Target size $30 \times 30$} \\
\hline & \multicolumn{6}{|c|}{ Dmm } & \multicolumn{6}{|c|}{ Dmm } \\
\hline & Concrete & Rock & Brick & Wood & Steel & Aluminum & Concrete & Rock & Brick & Wood & Steel & Aluminum \\
\hline 100 & -1 & -1 & -5 & -4 & -2 & -5 & -2 & -7 & -5 & -3 & -9 & -4 \\
\hline 200 & -8 & -4 & -3 & -6 & -8 & -8 & -3 & -2 & -5 & -3 & -13 & -10 \\
\hline 300 & -3 & -4 & -5 & -6 & -11 & -7 & -3 & -1 & -6 & 0 & -15 & -10 \\
\hline 400 & -11 & -10 & -9 & -6 & -17 & -6 & -6 & -4 & -1 & -5 & -10 & -7 \\
\hline 500 & -11 & -9 & -12 & -7 & -16 & -16 & -14 & -10 & -13 & -9 & -12 & -18 \\
\hline 600 & -14 & -17 & -29 & -22 & -16 & -26 & -12 & -14 & -17 & -13 & -22 & -22 \\
\hline 700 & -7 & -14 & -14 & -11 & -5 & -17 & -5 & -4 & -16 & -8 & -10 & -13 \\
\hline 800 & -11 & -15 & ---- & -13 & ---- & -20 & 0 & -1 & -12 & -5 & ---- & 7 \\
\hline 900 & -22 & -16 & ---- & -2 & -17 & -15 & -20 & -22 & -15 & -2 & -9 & -14 \\
\hline 1000 & -41 & -17 & ---- & -22 & -18 & -12 & -22 & -8 & -9 & -7 & -17 & -30 \\
\hline
\end{tabular}


Table 3. Deviations in the measured distances at incidence angle $=15^{\circ}$ for targets 5 and $10 \mathrm{~cm}$.

\begin{tabular}{|c|c|c|c|c|c|c|c|c|c|c|c|c|}
\hline \multirow[b]{3}{*}{ Dist } & \multicolumn{6}{|c|}{ Target size $5 \times 5$} & \multicolumn{6}{|c|}{ Target size $10 \times 10$} \\
\hline & \multicolumn{6}{|c|}{ Dmm } & \multicolumn{6}{|c|}{ Dmm } \\
\hline & Concrete & Rock & Brick & Wood & Steel & Aluminum & Concrete & Rock & Brick & Wood & Steel & Aluminum \\
\hline 100 & -1 & 2 & -2 & 0 & -4 & -4 & 2 & 3 & -1 & -1 & -3 & -4 \\
\hline 200 & -11 & -7 & -10 & -5 & -2 & -2 & 0 & -1 & -1 & -3 & -8 & -2 \\
\hline 300 & -9 & -11 & -4 & -15 & -16 & -23 & -5 & 2 & -7 & -3 & -20 & -2 \\
\hline 400 & -12 & -16 & -15 & -4 & -26 & -12 & -3 & -9 & -23 & -9 & -11 & -11 \\
\hline 500 & -7 & -10 & 2 & -8 & -25 & -3 & -18 & -17 & -20 & -12 & -20 & -25 \\
\hline 600 & -23 & -24 & ------ & -9 & ----- & -30 & -9 & -12 & -16 & -17 & -29 & -21 \\
\hline 700 & ------ & ------ & ------ & ------ & ------ & ------ & -19 & -16 & ------ & -11 & ------ & ------ \\
\hline 800 & ------ & ------ & ------ & ------ & ------ & ------ & ------ & ------ & ----- & ------ & ----- & ------ \\
\hline 900 & ----- & ----- & ----- & ----- & ----- & ----- & ----- & ----- & ----- & ----- & ----- & ----- \\
\hline 1000 & ------ & ------ & ------ & ------ & ------ & ------ & ------ & ------ & ------ & ------ & ------ & ------ \\
\hline
\end{tabular}

Table 4. Deviations in the measured distances at incidence angle $=15^{\circ}$ for targets 20 and $30 \mathrm{~cm}$.

\begin{tabular}{|c|c|c|c|c|c|c|c|c|c|c|c|c|}
\hline \multirow[b]{3}{*}{ Dist } & \multicolumn{6}{|c|}{ Target size $20 \times 20$} & \multicolumn{6}{|c|}{ Target size $30 \times 30$} \\
\hline & \multicolumn{6}{|c|}{ Dmm } & \multicolumn{6}{|c|}{ Dmm } \\
\hline & Concrete & Rock & Brick & Wood & Steel & Aluminum & Concrete & Rock & Brick & Wood & Steel & Aluminum \\
\hline 100 & 0 & -2 & -3 & -2 & 1 & -4 & 1 & -6 & -4 & -1 & -8 & -6 \\
\hline 200 & -4 & -3 & 0 & -2 & -5 & -3 & -2 & -1 & -1 & -2 & -8 & -4 \\
\hline 300 & 8 & 1 & -4 & -2 & -4 & -16 & 6 & 4 & -2 & 2 & 1 & -9 \\
\hline 400 & -12 & 0 & -7 & -7 & -32 & -5 & 5 & 3 & -17 & 0 & -5 & -14 \\
\hline 500 & -1 & 0 & -3 & -6 & -4 & -14 & -4 & -4 & 3 & -3 & -10 & -17 \\
\hline 600 & -1 & -10 & -9 & -8 & -8 & 14 & 0 & -11 & -1 & -13 & -14 & -11 \\
\hline 700 & -7 & -17 & -10 & -2 & ------ & ----- & -14 & 0 & -10 & -12 & ------ & ------ \\
\hline 800 & ----- & -14 & ----- & -13 & ------ & ----- & 4 & 3 & -3 & -2 & ----- & ----- \\
\hline 900 & -23 & -15 & ----- & -26 & ------ & ----- & -12 & -7 & ----- & -4 & ----- & ----- \\
\hline 1000 & ------ & -8 & ----- & -17 & ------ & ----- & -12 & 2 & ----- & -13 & ----- & ----- \\
\hline
\end{tabular}

Table 5. Deviations in the measured distances at incidence angle $=30^{\circ}$ for targets 5 and $10 \mathrm{~cm}$.

\begin{tabular}{|c|c|c|c|c|c|c|c|c|c|c|c|c|}
\hline \multirow[b]{3}{*}{ Dist } & \multicolumn{6}{|c|}{ Target size $5 \times 5$} & \multicolumn{6}{|c|}{ Target size $10 \times 10$} \\
\hline & \multicolumn{6}{|c|}{ Dmm } & \multicolumn{6}{|c|}{ Dmm } \\
\hline & Concrete & Rock & Brick & Wood & Steel & Aluminum & Concrete & Rock & Brick & Wood & Steel & Aluminum \\
\hline 100 & 3 & 1 & 1 & -1 & -10 & -9 & 4 & 4 & 1 & 1 & -2 & -13 \\
\hline 200 & -5 & -11 & -10 & -3 & -20 & -25 & -2 & 1 & -1 & 0 & -6 & -8 \\
\hline 300 & -11 & -9 & -10 & -13 & -28 & -24 & -3 & -1 & -3 & -10 & -25 & -21 \\
\hline 400 & -20 & -13 & -27 & -14 & -18 & -30 & -5 & -6 & -14 & -15 & -10 & -19 \\
\hline 500 & -12 & -9 & -10 & -7 & -19 & -3 & -13 & -8 & -4 & -10 & -27 & ------ \\
\hline 600 & -33 & -23 & ------ & -20 & ------ & ------ & -20 & -5 & ------ & -15 & ------ & ------ \\
\hline 700 & ------ & ------ & ------ & ------ & ------ & ------ & ------ & -2 & ------ & ------ & ------ & ------ \\
\hline 800 & ------ & ------ & ------ & ------ & ------ & ------ & ------ & ------ & ------ & ------ & ------ & ------ \\
\hline 900 & ------- & ------ & ------ & ------ & ------- & ------- & ------ & ------ & ------ & ------ & ------ & ------ \\
\hline 1000 & ------ & ------ & ------ & ------ & ------ & ------ & ------ & ------ & ------ & ------ & ------- & ------ \\
\hline
\end{tabular}


Table 6. Deviations in the measured distances at incidence angle $=30^{\circ}$ for targets 20 and $30 \mathrm{~cm}$.

\begin{tabular}{|c|c|c|c|c|c|c|c|c|c|c|c|c|}
\hline \multirow[b]{3}{*}{ Dist } & \multicolumn{6}{|c|}{ Target size $20 \times 20$} & \multicolumn{6}{|c|}{ Target size $30 \times 30$} \\
\hline & \multicolumn{6}{|c|}{ Dmm } & \multicolumn{6}{|c|}{ Dmm } \\
\hline & Concrete & Rock & Brick & Wood & Steel & Aluminum & Concrete & Rock & Brick & Wood & Steel & Aluminum \\
\hline 100 & -1 & -1 & -1 & 2 & -1 & -15 & 4 & -3 & 1 & -1 & -7 & -61 \\
\hline 200 & 2 & 1 & 5 & 1 & -2 & -29 & 5 & 5 & 1 & 4 & -4 & -33 \\
\hline 300 & 4 & 6 & 4 & 1 & ----- & 3985 & 4 & 14 & 5 & 7 & ----- & 3820 \\
\hline 400 & -11 & -1 & -2 & -7 & ----- & ----- & 14 & 1 & 7 & 5 & ----- & ----- \\
\hline 500 & 11 & 9 & 6 & 4 & 3 & -20 & 9 & 10 & 7 & 7 & ----- & ----- \\
\hline 600 & 4 & 11 & -6 & -2 & ----- & ----- & 1 & 18 & 4 & 0 & ----- & ----- \\
\hline 700 & -8 & -10 & ----- & -14 & ------ & ----- & 9 & 7 & -3 & 4 & ------ & ----- \\
\hline 800 & ----- & ------ & ------ & -11 & ------ & ----- & -3 & 9 & -16 & -7 & ----- & ----- \\
\hline 900 & ------ & -15 & ------ & ------ & ------ & ----- & 5 & 9 & ----- & -1 & ----- & ----- \\
\hline 1000 & ------ & -16 & ------ & -15 & ------ & ------ & -14 & 4 & ------ & -9 & ------ & ------ \\
\hline
\end{tabular}

Table 7. Deviations in the measured distances at incidence angle $=45^{\circ}$ for targets 5 and $10 \mathrm{~cm}$.

\begin{tabular}{|c|c|c|c|c|c|c|c|c|c|c|c|c|}
\hline \multirow[b]{3}{*}{ Dist } & \multicolumn{6}{|c|}{ Target size $5 \times 5$} & \multicolumn{6}{|c|}{ Target size $10 \times 10$} \\
\hline & \multicolumn{6}{|c|}{ Dmm } & \multicolumn{6}{|c|}{ Dmm } \\
\hline & Concrete & Rock & Brick & Wood & Steel & Aluminum & Concrete & Rock & Brick & Wood & Steel & Aluminum \\
\hline 100 & 1 & 3 & 3 & -2 & -21 & -24 & 5 & 5 & 2 & 3 & -6 & -141 \\
\hline 200 & -9 & -13 & -13 & -5 & -25 & -10 & -1 & 4 & -3 & -3 & -24 & -53 \\
\hline 300 & -18 & -9 & -19 & -15 & -9 & -31 & -6 & -1 & -17 & -19 & -31 & -6 \\
\hline 400 & -13 & -19 & -20 & -21 & -28 & 0 & -24 & -12 & -17 & -17 & -25 & -20 \\
\hline 500 & -11 & -5 & -5 & -12 & -7 & -17 & -16 & -13 & -14 & -13 & -24 & ----- \\
\hline 600 & ----- & ----- & ----- & ----- & ----- & ----- & -13 & 0 & ----- & -9 & ----- & ----- \\
\hline 700 & ------ & ----- & ------ & ----- & ----- & ----- & ------ & ----- & ----- & ----- & ----- & ------ \\
\hline 800 & ----- & ------ & ------ & ------ & ------ & ------ & ------ & ------ & ------ & ------ & ------ & ------ \\
\hline 900 & ------ & ------ & ------ & ----- & ------ & ------ & ----- & ----- & ----- & ----- & ----- & ----- \\
\hline 1000 & ----- & ----- & ----- & ----- & ----- & ----- & ----- & ----- & ----- & ----- & ----- & ----- \\
\hline
\end{tabular}

Table 8. Deviations in the measured distances at incidence angle $=45^{\circ}$ for targets 20 and $30 \mathrm{~cm}$.

\begin{tabular}{|c|c|c|c|c|c|c|c|c|c|c|c|c|}
\hline \multirow[b]{3}{*}{ Dist } & \multicolumn{6}{|c|}{ Target size $20 \times 20$} & \multicolumn{6}{|c|}{ Target size $30 \times 30$} \\
\hline & \multicolumn{6}{|c|}{ Dmm } & \multicolumn{6}{|c|}{ Dmm } \\
\hline & Concrete & Rock & Brick & Wood & Steel & Aluminum & Concrete & Rock & Brick & Wood & Steel & Aluminum \\
\hline 100 & -1 & -1 & 2 & 4 & -4 & 3639 & 6 & -2 & 3 & 5 & -13 & 3583 \\
\hline 200 & 10 & 12 & 12 & 7 & -2 & 3576 & 14 & 13 & 6 & 14 & -10 & 3549 \\
\hline 300 & 6 & 0 & 3 & 0 & ------ & ------ & 6 & 14 & 2 & 16 & ----- & 3797 \\
\hline 400 & -8 & -3 & -10 & 3 & ------ & ------ & 23 & 0 & 4 & 11 & ----- & ------ \\
\hline 500 & 10 & 13 & 17 & -5 & -14 & ----- & 7 & 11 & 21 & 17 & ------ & ----- \\
\hline 600 & -1 & 3 & -9 & -8 & ------ & ----- & 2 & 18 & 14 & 9 & ------ & ------ \\
\hline 700 & -19 & -16 & ------ & -18 & ------ & ------ & 1 & 5 & -16 & 6 & ------ & ------ \\
\hline 800 & ------ & ------ & ------ & ------ & ------ & ------ & ------ & 3 & ------ & -14 & ------ & ------ \\
\hline 900 & ------ & ------ & ------ & ------ & ------ & ------ & ------ & 14 & ------ & 5 & ------ & ------ \\
\hline 1000 & ------ & ------ & ------ & ------ & ------ & ------ & ------ & 8 & ------ & -25 & ------ & ------ \\
\hline
\end{tabular}


Table 9. Deviations in the measured distances at incidence angle $=60^{\circ}$ for targets 5 and $10 \mathrm{~cm}$.

\begin{tabular}{|c|c|c|c|c|c|c|c|c|c|c|c|c|}
\hline \multicolumn{7}{|c|}{ Target size $5 \times 5$} & \multicolumn{6}{|c|}{ Target size $10 \times 10$} \\
\hline \multicolumn{7}{|c|}{ Dmm } & \multicolumn{6}{|c|}{ Dmm } \\
\hline Dist & Concrete & Rock & Brick & Wood & Steel & Aluminum & Concrete & Rock & Brick & Wood & Steel & Aluminum \\
\hline 100 & -8 & 1 & 0 & -8 & -22 & -22 & 6 & 6 & 3 & 2 & -5 & 4283 \\
\hline 200 & -16 & -6 & -14 & -10 & -13 & -15 & -4 & -1 & -11 & -5 & -16 & -53 \\
\hline 300 & -12 & -10 & -16 & -24 & -32 & -15 & -18 & -8 & -16 & -18 & -34 & -16 \\
\hline 400 & -18 & -15 & -21 & -9 & -14 & -24 & -35 & -11 & -20 & -8 & -26 & -45 \\
\hline 500 & -9 & -13 & ------ & -2 & ------ & -13 & -22 & -21 & -12 & -11 & -24 & ------ \\
\hline 600 & ------ & ----- & ------ & ------ & ----- & ------ & -5 & -18 & ------ & ------ & ----- & ------ \\
\hline 700 & ------ & ------ & ------ & ------ & ------ & ------ & ------ & ------ & ------ & ----- & ------ & ------ \\
\hline 800 & ------ & ------ & ------ & ------ & ------ & ------ & ------ & ------ & ------ & ------ & ------ & ------ \\
\hline 900 & ------ & ------ & ------ & ------ & ------ & ------ & ------ & ------ & ----- & ------ & ------ & ------ \\
\hline 1000 & ------ & ----- & ----- & ----- & ----- & ---- & ----- & ----- & ------ & ------ & ------ & ----- \\
\hline
\end{tabular}

Table 10. Deviations in the measured distances at incidence angle $=60^{\circ}$ for targets 20 and $30 \mathrm{~cm}$.

\begin{tabular}{|c|c|c|c|c|c|c|c|c|c|c|c|c|}
\hline \multirow[b]{3}{*}{ Dist } & \multicolumn{6}{|c|}{ Target size $20 \times 20$} & \multicolumn{6}{|c|}{ Target size $30 \times 30$} \\
\hline & \multicolumn{6}{|c|}{ Dmm } & \multicolumn{6}{|c|}{ Dmm } \\
\hline & Concrete & Rock & Brick & Wood & Steel & Aluminum & Concrete & Rock & Brick & Wood & Steel & Aluminum \\
\hline 100 & -1 & 8 & 8 & 9 & -2 & 4096 & 9 & -1 & 9 & 8 & -13 & 3985 \\
\hline 200 & 22 & 13 & 22 & 15 & 3 & 4063 & 27 & 30 & 17 & 13 & ------ & 3903 \\
\hline 300 & -7 & -10 & -5 & -13 & ------ & ------ & -14 & 13 & 10 & 6 & ------ & 4368 \\
\hline 400 & -4 & -13 & -22 & -19 & ----- & -104 & 19 & -99 & 5 & 8 & ----- & ----- \\
\hline 500 & 12 & 12 & -9 & -13 & -13 & ----- & -5 & 12 & 35 & 18 & ----- & ----- \\
\hline 600 & 9 & -8 & -3 & 0 & ------ & ----- & 10 & 15 & 13 & 7 & ----- & ----- \\
\hline 700 & ------ & -22 & ------ & -32 & ------ & ------ & 0 & -1 & 13 & 19 & ------ & ----- \\
\hline 800 & ------ & ----- & ----- & ----- & ------ & ------ & ------ & ------ & ------ & ------ & ------ & ------ \\
\hline 900 & ------ & ----- & ----- & ---- & ---- & ----- & ----- & ----- & ----- & ----- & ----- & ----- \\
\hline 1000 & ------ & ----- & ------ & ----- & ----- & ------ & ------ & ------ & ------ & ----- & ----- & ------ \\
\hline
\end{tabular}

that make the instrument measures distances longer than that measured on the prism. Tables 1-10 show also that a target of size $5 \times 5 \mathrm{~cm}$ and $10 \times 10 \mathrm{~cm}$ can be used to measure distances up to $700 \mathrm{~m}$ at incidence angle $=0^{\circ}$ and up to $500 \mathrm{~m}$ at incidence angles up to $60^{\circ}$.

A target of size $20 \times 20 \mathrm{~cm}$ can be used to measure distances up to $1000 \mathrm{~m}$ at incidence angle $=0^{\circ}$ and up to $700 \mathrm{~m}$ at incidence angles greater than $30^{\circ}$. The light color targets of size $20 \times 20 \mathrm{~cm}$ can be used to measure distances up to $1000 \mathrm{~m}$ at incidence angles up to $30^{\circ}$.

A target of size $30 \times 30 \mathrm{~cm}$ can be used to measure distances up to $1000 \mathrm{~m}$ at incidence angle $=0^{\circ}$ and up to $700 \mathrm{~m}$ at incidence angles greater than $45^{\circ}$. The light color targets of size $30 \times 30 \mathrm{~cm}$ can be used to measure distances up to $1000 \mathrm{~m}$ at incidence angles up to $45^{\circ}$.

Steel target has an opposed behavior to the light color targets, as noticed from Tables 1-10. As the steel target size increases its ability to reflect the laser beam to the instrument decreases especially for incidence angles 
greater than $15^{\circ}$. While steel target of size $5 \times 5 \mathrm{~cm}$ and $10 \times 10 \mathrm{~cm}$ can be used to measure distances up to 500 $\mathrm{m}$, target of size $20 \times 20 \mathrm{~cm}$ and $30 \times 30 \mathrm{~cm}$ could not be used to measure distances greater than $200 \mathrm{~m}$. This may be because of the darkness of this material.

Aluminum target has a unique behavior, as it act as a mirror with target size $20 \times 20 \mathrm{~cm}$ and $30 \times 30 \mathrm{~cm}$ when the incidence angle increases $15^{\circ}$ as shown in Table 6 and Tables 8-10. The big deviations appear in the mentioned tables are due to the reflection of the laser beam on the aluminum target to the wall shown in Figure 2 at the right hand side of the measuring line.

To show the effect of the incidence angle on the accuracy of the measured distance, the average of the absolute deviations for all materials was calculated after eliminated the odd values and presented graphically in Figure 3 for the different target size. Deviations resultant when using targets of size $5 \times 5 \mathrm{~cm}, 10 \times 10 \mathrm{~cm}, 20 \times 20 \mathrm{~cm}$ and $30 \times$ $30 \mathrm{~cm}$ are shown in Figures 3(a)-(d) respectively. Figure 3 shows that the incidence angle of $15^{\circ}$ and $30^{\circ}$ almost gives the same results as incidence angle of $0^{\circ}$ for target size greater than $5 \times 5 \mathrm{~cm}$. It shows also that the incidence angle of 45 and 60 gave the highest deviations and reduce the measuring range.

Figure 4 presents deviations in the measured distances due to target size at different incidence angles. At incidence angle $=0^{\circ}$, the target size has no effect on the accuracy of the measured distance, it affects the measuring range as shown in Figures 4(a)-(c), which also show that at incidence angle $=15^{\circ}$ and $30^{\circ}$, the target size clearly influences the accuracy of the reflectorless measurements. As the target size increases the deviations in the measured distances from the true value of the distances decrease. At incidence angles $45^{\circ}$ and $60^{\circ}$, the target size has a small effect on the accuracy, as the accuracy is slightly improved with the enlargement of the target size as shown in Figure 4(d) and Figure 4(e). At incidence angle $60^{\circ}$, the measuring range is reduced for all target sizes.

\section{Conclusions}

This research was performed to evaluate the accuracy of long range reflectorless total station used in urban areas where the targets were made of different materials and the site conditions forced the observation angle to be not perpendicular to the targets From the results gotten from the experimental work of this research, the followings can be concluded:

1) The keystone of the experiment is the supporting base, which is designed and manufactured to assure the correct placement of all targets and the possibility to compare the measured distances to the true values.

2) The majority of the reflectorless measurements are shorter than the true distances.

3) A target size of $5 \times 5 \mathrm{~cm}$ could be used to measure distances up to $700 \mathrm{~m}$ at incidence angle $=0^{\circ}$ and distances up to $500 \mathrm{~m}$ at incidence angles up to $60^{\circ}$.

4) A target size of $20 \times 20 \mathrm{~cm}$ could be used to measure distances up to $1000 \mathrm{~m}$ at incidence angle up to $30^{\circ}$ and distances up to $700 \mathrm{~m}$ at incidence angles up to $60^{\circ}$.

5) Target size has no effect on the accuracy of the measured distance at incidence angle $=0^{\circ}$

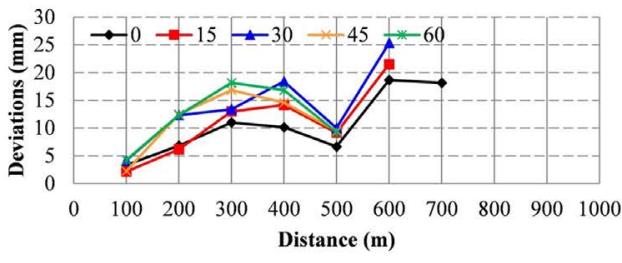

(a)

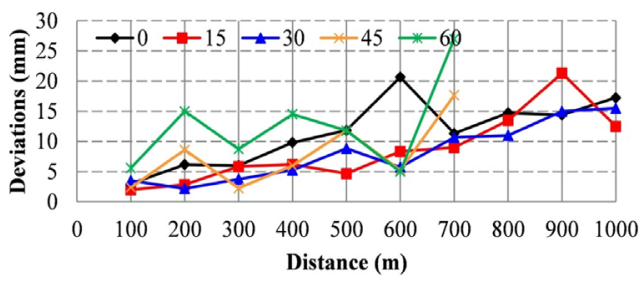

(c)

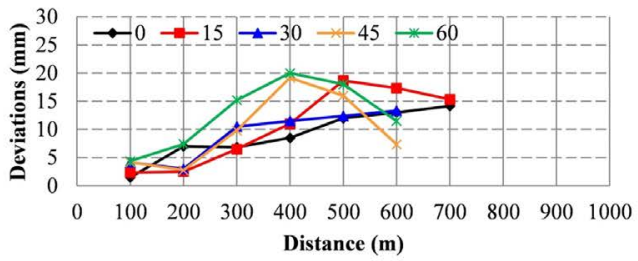

(b)

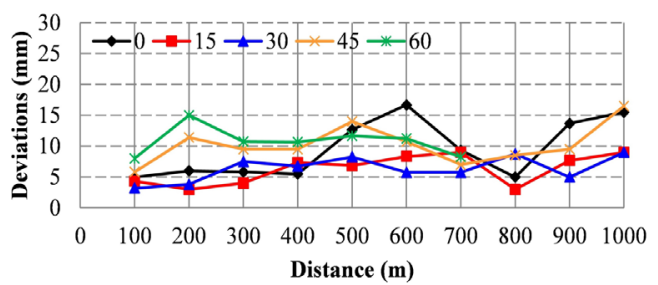

(d)

Figure 3. Average deviations for incidence angles with target size, a) $5 \times 5 \mathrm{~cm}$; b) $10 \times 10 \mathrm{~cm}$; c) $20 \times 20 \mathrm{~cm}$; d) $30 \times 30 \mathrm{~cm}$. 


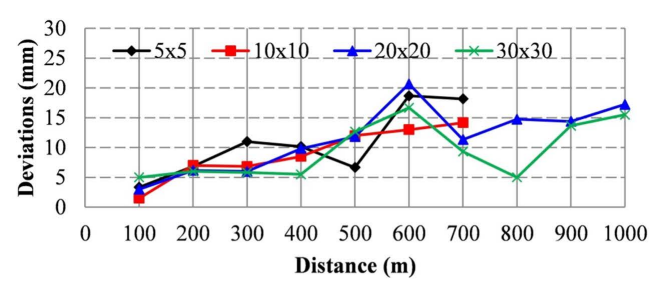

(a)

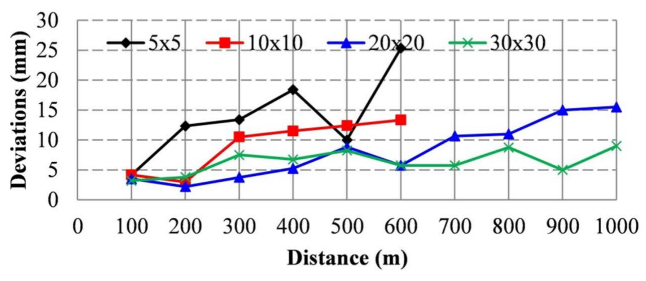

(c)

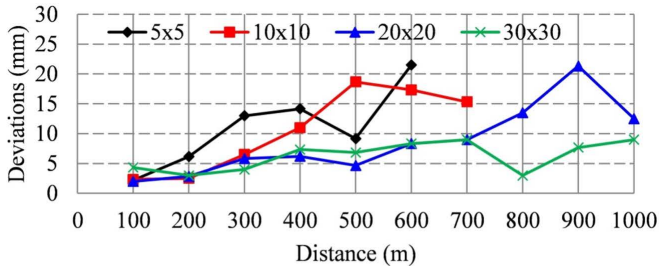

(b)

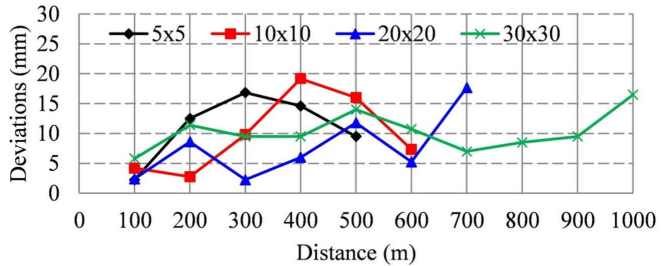

(d)

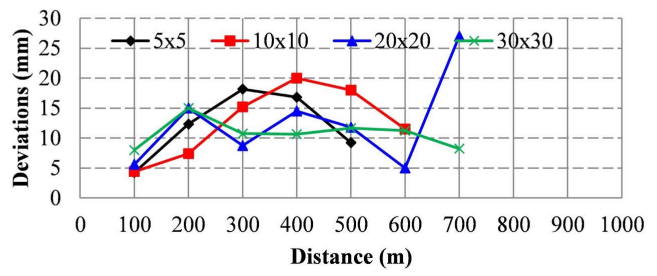

(e)

\section{Figure 4. Average deviations for target size with incidence angle, a) $0^{\circ}$; b) $15^{\circ}$; c) $30^{\circ}$; d) $45^{\circ}$; e) $60^{\circ}$.}

6) Target size is in direct proportion to the measuring accuracy at incidence angles $15^{\circ}$ and $30^{\circ}$ and has a slight positive influence on the accuracy at incidence angles greater than $30^{\circ}$.

7) The incidence angle up to $30^{\circ}$ has approximately no influence on the accuracy of the measured distances or the measuring range.

8) The incidence angle greater than $30^{\circ}$ decreases the accuracy of the measured distances and reduces the measuring range.

9) The measuring range is reduced dramatically with enlargement of the target size of steel and aluminum at incidence angles greater than $15^{\circ}$.

10)Aluminum targets may act as mirrors at incidence angles greater than $30^{\circ}$.

\section{Acknowledgements}

Thanks are due to Mr. Talal Al-Thebety and Mr. Said Hesiki for assistance in performing the field measurements.

\section{References}

[1] Khalil, R. (2013) The Accuracy of GIS Tools for Transforming Assumed Total Station Surveys to Real World Coordinates. Journal of Geographic Information System, 5, 486-491. http://dx.doi.org/10.4236/jgis.2013.55045

[2] Holley, P., Perrine, Th. and Gamble, T. (2011) Is Reflectorless EDM Technology Reliable for Building Construction Layout Tolerances? Proceedings of 47th ASC Annual International Conference, Omaha, 6-9 April 2011. http://ascpro0.ascweb.org/archives/cd/2011/paper/CPGT333002011.pdf

[3] Cosser, E., Roberts, G., Meng, X. and Dodson, A. (2003) Measuring The Dynamic Deformation Of Bridges Using A Total Station. Proceedings of 11th International FIG Symposium on Deformation Measurements, Santorini, 25-28 May 2003. http://www.fig.net/resources/proceedings/before_2005/santorini_comm6/I-Monitoring\%20Static\%20and\%20Dyn/I9.pdf

[4] Haddad, N. and Ishakat, F. (2007) 3D Laser Scanner and Reflectorless Total Station: A Comparative Study of the Slots 
of El-Khazneh at Petra in Jordan. Proceedings of XXI International CIPA Symposium, Athens, 1-6 October 2007. http://cipa.icomos.org/fileadmin/template/doc/ATHENS/FP070.pdf

[5] Lambrou, E. and Pantazis, G. (2010) Evaluation of the Credibility of Reflectorless Distance Measurement. Journal of Surveying Engineering, 136, 165-171. http://dx.doi.org/10.1061/(ASCE)SU.1943-5428.0000029

[6] Gopi, S., Sathikumar, R. and Madhu, N. (2007) Advanced Surveying: Total Station, GIS and Remote Sensing. Dorling Kindersley Pvt. Ltd., India.

[7] Tucker, C. (2002) Testing and Verification of the Accuracy of 3D Laser Scanning Data. Proceedings of Symposium on Geospatial Theory, Processing and Applications, Ottawa, 9-12 July 2002. http://www.isprs.org/proceedings/XXXIV/part4/pdfpapers/537.pdf

[8] Mills, J. and Barber, D. (2004) Geomatics Techniques for Structural Surveying. Journal of Surveying Engineering, 130, 56-64. http://dx.doi.org/10.1061/(ASCE)0733-9453(2004)130:2(56)

[9] Coaker, L.H. (2009) Reflector-Less Total Station Measurements and Their Accuracy, Precision and Reliability. USQ Project, Unpublished. http://eprints.usq.edu.au/id/eprint/8530

[10] Yan, F., Ullah, M.R., Gong, Y.X., Feng, Z.K., Chowdury, Y. and Wu, L.L. (2012) Use of a No Prism Total Station for Field Measurements in Pinus tabulaeformis Carr. Stands in China. Biosystems Engineering, 113, 259-265. http://dx.doi.org/10.1016/j.biosystemseng.2012.08.007

[11] Key, H. and Lemmens, M. (2005) Reflectorless Laser Distance Measurement. GIM International, 2, 19.

[12] Beshr, A. and Abo Elnaga, I. (2011) Investigating the Accuracy of Digital Levels and Reflectorless Total Stations for Purposes of geodetic Engineering. Alexandria Engineering Journal, 50, 399-405. http://dx.doi.org/10.1016/j.aej.2011.12.004

[13] Topcon 7500 Specifications. http://www.topptopo.dk/uploads/media/manualer/Totalstation/IM GPT-7500Eng.pdf 